Old Dominion University

ODU Digital Commons

1973

\title{
Effect of Air Bubble Solution on Air-Sea Gas Exchange
}

Larry P. Atkinson

Old Dominion University, latkinso@odu.edu

Follow this and additional works at: https://digitalcommons.odu.edu/ccpo_pubs

Part of the Atmospheric Sciences Commons, Climate Commons, and the Oceanography Commons

\section{Original Publication Citation}

Atkinson, L. P. (1973). Effect of air bubble solution on air-sea gas exchange. Journal of Geophysical Research, 78(6), 962-968. doi:10.1029/JC078i006p00962

This Article is brought to you for free and open access by the Center for Coastal Physical Oceanography at ODU Digital Commons. It has been accepted for inclusion in CCPO Publications by an authorized administrator of ODU Digital Commons. For more information, please contact digitalcommons@odu.edu. 


\title{
Effect of Air Bubble Solution on Air-Sea Gas Exchange
}

\author{
LARRY P. ATKINSON ${ }^{1}$ \\ Department of Oceanography, Dalhousie University \\ Halifax, Nova Scotia, Canada
}

\begin{abstract}
Recent data on ambient wave generated oceanic bubble spectra (Medwin, 1970) permit the calculation of the influence of bubble solution on air-sea gas exchange. Schulkin's formula is used to estimate the depth variation of bubbles, and a square law is used to estimate the increase of bubble volume with wind speed. Calculations indicate that bubble solution can be a very significant factor in gas exchange. Bubble solution enhances gas input and retards degassing of the water column. Preliminary data show a lag time of about 5 hours in the response of the water column to an atmospheric pressure change.
\end{abstract}

Although there have been few measurements of air-sea gas exchange, nearly all reports on such measurements point out the possible participation of bubbles; Redfield [1948] calculated gas exchange coefficients for the Gulf of Maine and felt that the seasonal variation in the gas exchange coefficient could be explained by 'waves, spindrift, and the bubbles.' In his summary of gas exchange measurements in tanks Kanwisher [1963] mentions that bubbles must be important in gas exchange, and he stresses the need to know the volume flux of bubbles under various sea conditions. There have been several experimental tank measurements of gas exchange coefficients; there is a revealing difference between these experimental measurements and coefficients measured (often very indirectly) in the ocean. Schink et al. [1970] summarized the experimental and oceanic measurements; the higher gas exchange coefficients were attained in natural conditions. The one characteristic definitely missing from experimental measurements is the large breaking wave with resultant bubble production.

Measurements of oceanic gas concentrations have led to speculation and recently to some definite evidence for gas concentration control by bubble solution. Benson and Parker [1961, p. 249] felt that, although their $\mathrm{N}_{2} / \mathrm{Ar}$ data were near $\mathrm{N}_{2}^{\prime} / \mathrm{Ar}^{\prime},{ }^{\prime} \ldots$ it is interesting to note

${ }^{1}$ Now at Skidaway Institute of Oceanography, Savannah, Georgia 31406.

Copyright (ㄷ) 1973 by the American Geophysical Union. that the experimental curve $\left(\mathrm{N}_{2} / \mathrm{Ar}\right)$ lies above the theoretical curve $\left(\mathrm{N}_{2}^{\prime} / \mathrm{Ar}^{\prime}\right)$ at high temperatures where most surface waters are represented. This would be expected if trapping of air bubbles from surface turbulence were significant. . . Bieri [1971] and Craig and Weiss [1971] presented values of up to $10 \%$ for the amount of air injected into the water by bubble solution.

The production of bubbles by breaking waves and the presence of bubbles in the upper few meters of the ocean are facts accepted by anyone who has had the opportunity to be at sea. In a stormy sea the position of a breaking wave is marked for minutes by a greenish blue patch of bubble-laden water contrasted against the normal oceanic blue. As the wind speed rises, the sea surface becomes increasingly covered with foam patches until, during hurricane conditions, the sea surface becomes undefinable because of the confusion of breaking waves, bubbles, and spray. Bubbles produced by a breaking wave are carried down the water column by vertical turbulence. Visual observations from the bow port of the R.V. Atlantis led Kanwisher [1963] to estimate that bubbles penetrated the water column to a depth equal to $2-3$ times the wave height. On the average, especially at a higher wind speed and a higher density of breaking waves, the bubble density at a given locality in the water column will remain constant, even though bubbles are constantly passing through the given locality. Under normal circumstances these bubbles will go into solution because of hydrostatic pressure and 
surface tension. Therefore they represent a source of dissolved gas distributed throughout the water column. This paper demonstrates the magnitude and characteristics of bubble solution of air-sea gas exchange.

\section{Spectra and Solution Rates of Bubbles}

Because of recent advancements in underwater acoustical research, limited data are available on the size-frequency relationship of bubbles in the surface layer of the ocean; unfortunately, acoustical methods are not reliable at high bubble populations, and no measurements have been made above sea state 2 (wind speed $U=3 \mathrm{~m} / \mathrm{sec})$. Medwin [1965, 1970] used both attenuation and backscattering techniques to measure spectra of bubbles in an isothermal oceanic surface layer during sea state 2 . His observations agree qualitatively with results of wind tank experiments by Glotov et al. [1962]; a maximum is found at $0.005-0.0150$ $\mathrm{cm}$. Medwin's results compare quantitatively with the visual observations of Blanchard and Woodcock [1957] (see Medwin [1970, Figure 6]). This agreement exists even though the Blanchard and Woodcock observations were in the surf zone and Medwin's were during sea state 2 in the open ocean, when few waves are breaking. Monahan [1971] has shown that no breaking waves are present at wind speeds of $<3.6 \mathrm{~m} / \mathrm{sec}$. If this is true, Medwin's values at a wind speed of about $3 \mathrm{~m} / \mathrm{sec}$ may be fortuitous, but regardless these values do agree with Blanchard and Woodcock's and will adequately serve as a base for the following calculations. Figure 1 shows a typical oceanic bubble spectrum adapted from Medwin [1970, Figure 6]; the maximum frequency at about $0.01 \mathrm{~cm}$ is a result of the high solution rates of small bubbles and the high buoyancy of larger bubbles. Turner [1961] has shown that bubbles with a radius of $<0.0050 \mathrm{~cm}$ are stable; although they may appear in a measured spectrum, they are not contributing gas to the water column via bubble solution. The $N(r$, $U, z)$ refers to the number of bubbles of radius $r$ during wind speed $U$ at depth $z$. The radius bandwidth $d r$ is $0.0001 \mathrm{~cm}(1 \mu \mathrm{m})$.

\section{Depth Dependence of Bubble Spectra}

Schulkin [1969] used the following equation as an estimate of the depth dependence of bubble spectra:

$$
\begin{aligned}
& N(r, U, z)=N(r, U, 1) \\
& \cdot(1-z / L)^{1 / 2}(1+z / 11)^{1 / 2} z^{-1 / 2}
\end{aligned}
$$

where $z$ is the depth in yards and $N(r, U, 1)$ is the bubble density of radius $r$ at the surface $\left(z=\right.$ yard). For dimensional correctness, $z^{-1 / 2}$ is understood to mean $(z / 1 \mathrm{yd})^{-1 / 2}$. According to Schulkin, $(1-z / L)^{1 / 2}$ represents the mixing property of the isothermal layer, $z^{-1 / 2}$ is the natural decay of bubble density with depth, and $(1+z / 11)^{1 / 2}$ is the contribution of deeper nonsurface bubble sources or bubbles released in air-saturated water by decompression at the crests of internal waves. The actual importance of the decompression process in bubble production is unknown; however, the $(1+z / 11)^{1 / 2}$ term makes a relatively small contribution to $N(r, U, z)$ and will be retained for completeness. The $z^{-1 / a}$ term creates a problem because, as $z$ approaches 0 from $1, z^{-1 / a}$ approaches infinity. This could be avoided by using $e^{-*}$, but, for the sake of using Schulkin's complete formula, $z^{-1 / 2}$ will be retained. It must be remembered that the surface refers to 1 meter or 1 yard. For the purposes of the study it is assumed that meters and yards are equivalent. Equation 1 is shown in Figure 2 for a mixed layer depth of 10 and 20 meters. Bubble fre-

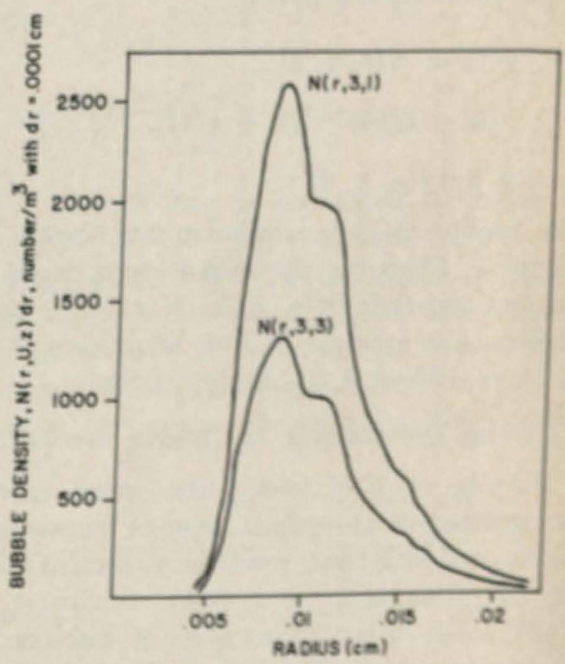

Fig. 1. Medwin's $N(r, 3,3)$ size frequency bubble spectrum and the calculated surface spectrum. 


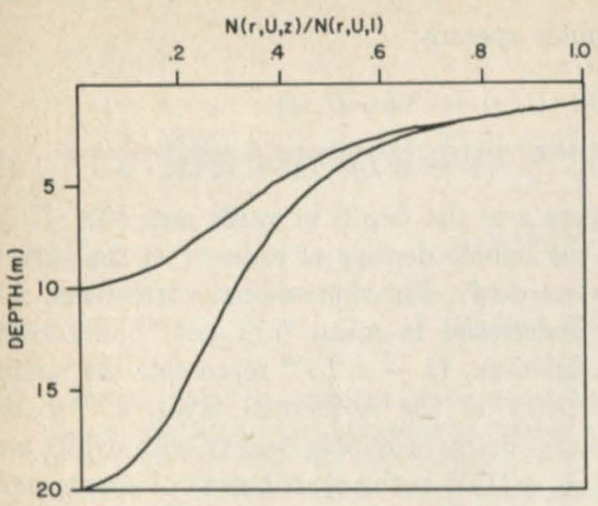

Fig. 2. Bubble frequency versus depth normalized to the surface spectra $N(r, U, 1)$.

quency is expressed as a fraction of the frequency at 1 meter. There is a rapid drop of bubble density in the first 5 meters, then a more gradual decrease to the bottom of the mixed layer.

\section{Calculations of Surface Bubble Spectra}

The only data of any use in calculating surface bubble spectra are from Medwin [1970, Figure 6]. These data are from sea state 2 $(U=3 \mathrm{~m} / \mathrm{sec})$ and a depth of 3 meters $(z=$ 3 meters). If we use (1) and a mixed layer depth of 10 meters ( $L=10$ meters), Medwin's data are converted to a $U=3$ surface spectrum by the following calculation:

$$
\begin{aligned}
& N(r, 3,1)=N(r, 3,3) \\
& \quad \cdot(1-z / 10)^{-1 / 2}(1+z / 11)^{-1 / 2} 3^{-1 / 2} \\
& \cong 2.0 N(r, 3,3)
\end{aligned}
$$

The results of this calculation are shown in Figure 1. Changing the mixed layer depth $L$ changes the ratio $N(r, 3,1) / N(r, 3,3)$ only slightly. For example, if $L=20$ meters, $N(r$, $3,1)=1.8 N(r, 3,3)$, a $10 \%$ change.

\section{Wind Dependence of Bubble Spectra}

Schulkin [1969] found that sound energy transmitted in the mixed layer is increasingly attenuated with rising wind; he attributed much of the attenuation to bubbles. Glotov et al. [1962] felt that the number of bubbles increased exponentially with wind speed during his tank experiments, although other lines of evidence would justify the use of a square extrap- olation to estimate the increase of bubble density with wind speed. For example, it is well known that wind stress increases with approximately the square of the wind sperd, and Kanwisher [1963] and Downing and Truesdale [1955] found gas exchange rates to increase with the square of the wind speed. Bionchard [1963] found a square law dependence of whitecap coverage on wind speed. More recently, Monahan [1971] has demonstrated i dependence on the 3.3 power of the wind.

To calculate the surface bubble spectra for wind speeds other than $3 \mathrm{~m} / \mathrm{sec}$, a square law is used to keep the calculation as conservative as possible.

$$
N(r, U, 1)=a U^{2}
$$

where $a$ is a radius dependent proportionality coefficient. No doubt $a$ is some function of wind speed; at higher wind speeds large bubbles stay in suspension longer as increased turbulence overcomes buoyancy forces. The exact relationship is not known and will have to be ignored in this study. Here $a$ is calculated for each radius at $U=3$ then used to calculate $N(r, U$, 1) for various values of $U$. That is,

$$
\begin{aligned}
a & =N(r, 3,1) / 3^{2} \\
N(r, U, 1) & =N(r, 3,1) U^{2} / 3^{2}
\end{aligned}
$$

A table was then prepared listing surface bubble spectra versus wind speed.

\section{Solution Rate of Bubbles}

Bubble solution rates are quite well known, and the following derivations are from Wyman et al. [1952] and Blanchard and Woodcock [1957]. According to the general gas law,

$$
n=4 \pi r^{3} p / 3 R T
$$

where $n$ is the number of moles of gas in the bubble, $R$ is the gas constant, $T$ is the absolute temperature, $r$ is the bubble radius, and $p$ is the pressure in the bubble. If the surface tension is included, as it should be, the pressure in the bubble will be atmospheric pressure plus hydrostatic pressure plus $2 \gamma / r$, the pressure due to surface tension. According to Fick's law of diffusion,

$$
d n / d t=-\delta 4 \pi r^{2}\left(p+2 \gamma / r-p_{0}\right)
$$


where $2 \gamma / r$, the pressure due to surface tension, is included, $p_{0}$ is the partial pressure of air in the bulk water, and $\delta$ is a constant defined by $\Delta s / d$, where $\Delta$ is the diffusion constant of air in water, $s$ is the solubility of air in water, and $d$ is the shell thickness of water around the bubble across which the diffusion gradient occurs. Differentiating (5) with respect to time and then equating that with (6) and substituting $d V=4 \pi r^{2} d r$, we obtain the following equation:

$$
\begin{array}{r}
d V / d t=-\delta R T 12 \pi r^{2}\left[r\left(p-p_{0}\right)\right. \\
+2 \gamma] /(3 p r+4 \gamma)
\end{array}
$$

If we use the values $R T=2.4 \times 10^{4} \mathrm{~cm}^{3} \mathrm{~atm} /$ mole, $\gamma=76 \times 10^{-6} \mathrm{~atm} \mathrm{~cm}, \delta=5 \times 10^{-9}$ $\mathrm{mole} / \mathrm{cm}^{2}$ sec atm [Wyman et al., 1952] and let $p=1+(z / 10),(7)$ reduces to

$$
\begin{aligned}
& d V / d t=4.52 \times 10^{-3} r^{-3}\left[z / 10+1-p_{0}\right. \\
& \left.+2\left(76 \times 10^{-6}\right) / r\right] /[3(z / 10+1) r \\
& \left.+4\left(76 \times 10^{-6}\right)\right]
\end{aligned}
$$

The sign was changed to denote input of gas to the water column. Here $p_{0}$ will normally be near $1 \mathrm{~atm}$, and thus it is indicated that the water is saturated.

\section{Source Strength Calculation}

The source strength $S(z)$ is the time rate of diffusion of a volume of gas bubbles with a radius between $r$ and $r+d r$ per unit volume of liquid at depth. At each depth, $S(z)$ is

$$
S(z)=\int_{0}^{\infty}\left(\frac{d V}{d t}\right)_{z, r} N(r, U, z) d r
$$

To apply this integral to the data derived from Medwin's observations, the following summation is used:

$$
S(z)=\sum_{r=0.0045}^{0.02} 5\left(\frac{d V}{d t}\right)_{z . r} N(r, U, z)
$$

The surface spectrum was digitized at 0.0005 - $\mathrm{cm}$ intervals, and so the 5 is placed in (10) to change to a $0.0001-\mathrm{cm}$ interval for summation. The $d V / d t$ is calculated by using (8). Figure 3 shows the results of these calculations for $L=$ 20 meters and $U=10,20,30$, and $40 \mathrm{~m} / \mathrm{sec}$. Between 0 and 1 meter, $S(z)$ cannot be calculated because, as was mentioned earlier, the

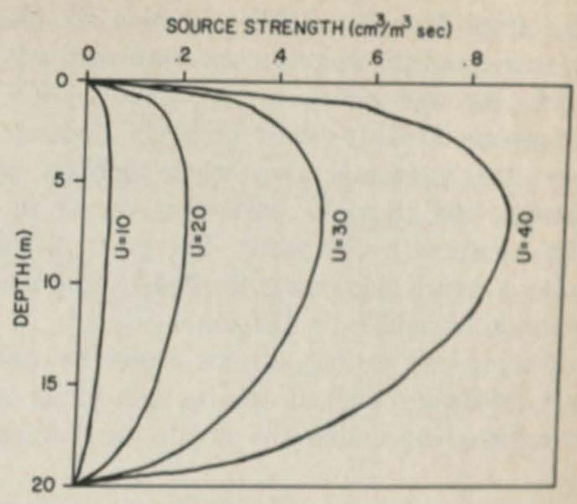

Fig. 3. Source strength versus depth at various wind speeds.

depth distribution equation (1) goes to infinity between 1 and 0 . Intuitively, I feel that the source strength must be very near 0 at the surface, since the bubble solution rate $d V / d t$ as calculated by equation (8) is near 0 at $z=$ 0 . Therefore $S(z)$ is extrapolated from $S(1)$ to $S(0)=0$.

\section{Estimate of Flux Due to Bubble Solvtion}

The source strength at each depth also represents a flux of gas across the air-sea interface. By integrating the source strength (9) with depth, a surface flux can be calculated:

$$
\begin{aligned}
\text { Flux } & =\int_{0}^{L} S(z) d z \\
= & \int_{0}^{L} \int_{0}^{\infty}\left(\frac{d V}{d t}\right)_{t, r} N(r, U, z) d r d z
\end{aligned}
$$

The surface flux is calculated by using the

\begin{tabular}{|c|c|c|}
\hline Nind, $=/ \sec$ & Flex, $\operatorname{cn}^{3} / \mathrm{cm}^{2} \sec$ & $\begin{array}{c}\text { Corrected Flise, } \\
\mathrm{ca}^{3} / \mathrm{cm}^{2} \text { sec }\end{array}$ \\
\hline $\begin{array}{l}10 \\
20 \\
30 \\
40\end{array}$ & $\begin{array}{r}0.7 \times 10^{-6} \\
3.5 \times 10^{-6} \\
7.3 \times 10^{-6} \\
13.9 \times 10^{-2}\end{array}$ & $\begin{array}{r}0.017 \times 10^{-2} \\
0.9 \times 10^{-2} \\
7.3 \times 10^{-2} \\
13.9 \times 10^{-2}\end{array}$ \\
\hline
\end{tabular}
estimate of (10) for the inner integral. The results are in Table 1. Since this flux is only in the area where whitecaps (and thus bubbles) occur, it must be corrected to represent an average flux for each square centimeter of the surface of the sea. The corrected flux is calcu-

TABL 1. Calculated Flus at Various wind Speeds for $L=20$ Neters 
lated from Monahan [1971, equation 6]. This equation predicts whitecap coverage with wind speed. As was noted by Blanchard [1971], Monahan's [1971] values probably underestimate the horizontal area where bubbles are present, and thus the correction results in a very conservative estimate. The point is that quite a respectable flux is implied by the mere presence of bubbles in the water column.

Similar implications ean be found by using only Medwin's original spectra and minor assumptions concerning the depth distribution.

\section{Comparison with a Storm Required Flux}

During the passage of a typical storm the atmospheric pressure may fall and rise 10 to 20 $\mathrm{mm} \mathrm{Hg}$ or about $1-2 \%$. During the pressure change, gas will transfer from one phase to another at a rate dependent on the partial pressure difference and wind. If we assume a $20-\mathrm{mm} \mathrm{Hg}$ pressure drop during 12 hours and a 20 -meter mixed layer, a flux of $-1.8 \times 10^{-4}$ $\mathrm{cm}^{3}$ air $/ \mathrm{cm}^{2}$ sec would be required to maintain equilibrium. Then, as the pressure rises, the flux would be $+1.8 \times 10^{-4} \mathrm{~cm}^{3}$ air $/ \mathrm{cm}^{2} \mathrm{sec}$. If the wind speed is $20 \mathrm{~m} / \mathrm{sec}$ on the average, the solution of bubbles can contribute approximately $0.9 \times 10^{-4} \mathrm{~cm}^{3} / \mathrm{cm}^{2} \mathrm{sec}$, or half the flux required to maintain equilibrium. It is clear that the solution of bubbles significantly affects the flux of air in and out of the water column. In fact, bubbles may be a severe impediment to degassing of the water column.

\section{Comparison with Seasonally Required Flux}

The normal seasonal heating and cooling of the water column causes gas to move across the interface. The flux is dependent on the amount of heating or cooling. In temperate latitudes the mixed water column may vary $20^{\circ} \mathrm{C}$. If we assume a 20 -meter water column and a normal salinity, the seasonal change would cause a flux of $8.5 \times 10^{-7} \mathrm{~cm}^{3} / \mathrm{cm}^{2} \mathrm{sec}$. Of course, this is the average for a season, and it could be expected that at times of extreme heating or cooling the required flux could be much higher. Redfield [1948] found the annual exchange in the Gulf of Maine to be $1.9 \times$ $10^{-6} \mathrm{~cm}^{3} / \mathrm{cm}^{2} \mathrm{sec}$. These values are again much less than the $\sim 10^{-4}-\mathrm{cm}^{3} / \mathrm{cm}^{2}$ sec flux resulting from bubble solution.

\section{One-Way Effect and Lag Tmis}

Clearly, one of the incongruities in considering the role of bubbles in interfacial mass transfer is the one-way effect. Bubbles and their solution cause a transfer of gas into the water column because, once a bubble enters the main part of the water column, it will never reach the surface. Only bubbles that penetrate just the upper meter or so have any chance of reaching the surface before disappearing because of solution. Thus the effect of bubble solution on gas transfer from air to water is much easier to visualize than that from water to air. In this paper, only the air-water route will be considered. Since the object of this paper is to show that bubbles can indeed affect gas transfer in a substantial way, this limitation is valid. A theoretical development that considers the motion of a bubble in the velocity field of a breaking wave and turbulent mixed layer could lead to new insight into the problem.

If we assume a steadily changing atmospheric pressure, the gas content of the water column should decrease or increase correspondingly. Figure 4 shows how the expected integrated gas content of the mixed water column changes with time in response to changing atmospheric pressure. As atmospheric pressure drops, the total gas in the water column begins to decrease but lags behind the pressure drop. This lag results from the gas input by bubble solution and the mixing characteristics of the water column. As the atmospheric pressure begins to rise again, the water column gas content increases but again lags behind the rise in atmospheric pressure by an amount less than that during degassing. The lag here is caused by the

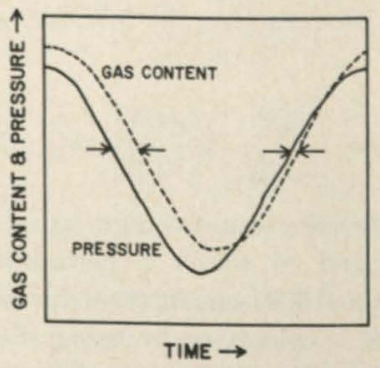

Fig. 4. Variation of mixed-layer gas content with changing pressure. Left center arrows indicate gassing lag, and right center arrows indicate degassing lag. Units are arbitrary. 
mixing characteristics of the water column.

Data obtained from the offshore oil rig Sedneth- 1 give an indication of the effect of lag time. Figure 5 shows a plot of the difference between the averages of the 0 - and 4-meter and the 8- and 12-meter $\mathrm{N}_{2}$ samples. With a pressure drop of $17 \mathrm{mb}$ the gas content in the 0 - to 6-meter interval drops in relation to the 6- to 12-meter interval, and thus it is indicated that the deeper waters of the mixed layer are not in contact with the interface as much as the surface water, as would be expected. The wind during the period started at $25 \mathrm{~m} / \mathrm{sec}$, fell to $9 \mathrm{~m} / \mathrm{sec}$, and toward the end rose to $16 \mathrm{~m} / \mathrm{sec}$. The data show how the water column does not act as a thoroughly mixed bulk waterinterface water system but rather the waters of the mixed layer have sporadic depth dependent encounters with the surface. A lag time of approximately 5 hours is indicated.

\section{Conclusion}

The simple calculations that were made clearly indicate a potential gas flux into the

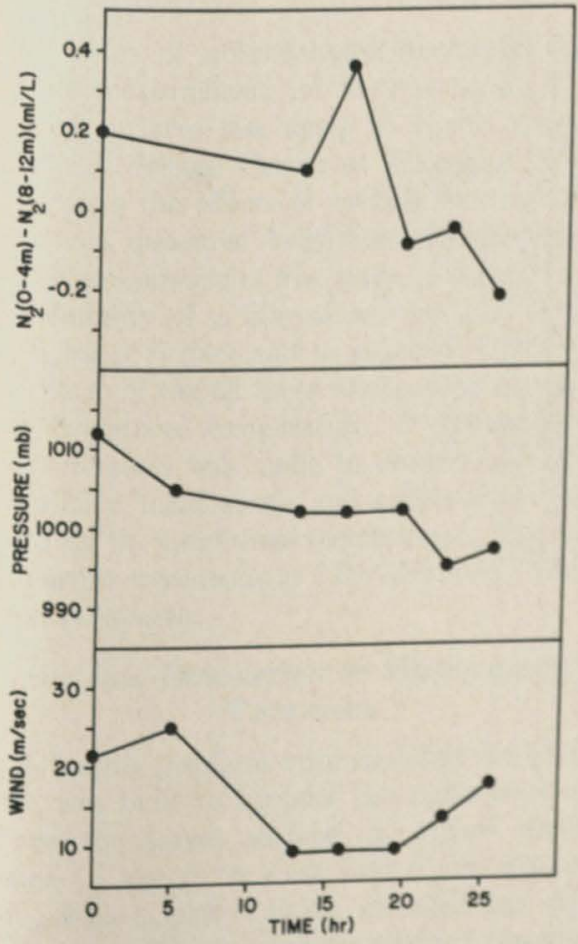

Fig. 5. Change of relative amounts of $\mathrm{N}$, in the water column in response to dropping pressure. water column resulting from a bubble solution of about $10^{-4} \mathrm{~cm}^{3} / \mathrm{cm}^{2}$ sec. With even more conservative estimates of bubble populations and lower solution rates because of organic films, the potential flux is still considerable. The one-way effect surely causes higher rates of ingassing relative to degassing. Further theoretical treatment could consider the motions of bubbles in the turbulent mixed layer. This approach would be analogous to particle motion theories with the added complications of buoyancy and depth and radius dependent solution rates. The implications of air bubble solution on the distribution of gases in the mixed layer is discussed by Atkinson [1972], and a paper is being prepared on the subject.

Acknowledgments. I wish to acknowledge the discussions with Drs. P. Wangersky, R. Cooke, R. Overstreet, and Mr. T. Yoshinari. This work was part of a Ph.D. thesis submitted to Dalhousie University. Shell Oil Canada, Ltd. is thanked for their cooperation during the use of the offshore oil rig Sedneth-1.

Support was provided by Dalhousie University, National Research Council of Canada, and the Department of Energy, Mines, and Resources.

\section{REFERENCES}

Atkinson, L. P., Air bubbles in an oceanic mixed layer: Effect on gas concentrations and air-eea gas exchange, $\mathrm{Ph} . \mathrm{D}$. thesis, Dalhousie University, Halifax, Nova Scotia, 1972.

Benson, B. B., and P. M. Parker, Nitrogen/argon and nitrogen isotope ratios in aerobic seawater, Deep Sea Res., 7, 237-253, 1961.

Bieri, R. H., Dissolved noble gases in marine waters, Earth Planet. Sci. Lett., 10, 329-333, 1971.

Blanchard, D. C., The electrification of the atmosphere by particles from bubbles in the sea, Progr. Oceanogr., 1, 71-202, 1963.

Blanchard, D. C., Whitecaps at sea, J. Atmos. Sci., $28,645,1971$.

Blanchard, D. C., and A. H. Woodeock, Bubble formation and modification in the sea and its meteorological significance, Tellus, 9, 145-157, 1957.

Craig, H., and R. F. Weiss, Dissolved gas saturation anomalies and excess helium in the ocean. Barth Planet. Sci. Lett., 10, 289-296, 1971.

Downing, A. L., and G. A. Truesdale, Some factors affecting the rate of solution of oxygen in water. J. A ppl. Chem., 5, 570-581, 1955.

Glotov, V. P., P. A. Kolobaev, and G. G. Neuimin, Investigation of the scattering of sound waves by bubbles generated by an artificial wind in seawater and the statistical distribution of bubble sires, Sov. Phys. Acoust., 7, 341-345, 1962. 
Kanwisher, J., On the exchange of gases between the atmosphere and the sea, Deep Sea Res., 10, 195-207, 1963.

Medwin, H., Design and use of an acoustic spectrometer for the detection of particulate matter and bubbles in the sea, paper presented at 5 th International Congress on Acoustics, Liège, Belgium, 1965.

Medwin, H., In situ acoustic measurements of bubble populations in coastal ocean waters, $J$. Geophys. Res., 75, 599-611, 1970.

Monahan, E. C., Oceanic whitecaps, J. Phys. Oceanol., 1, 139-144, 1971.

Redfield, A. C., The exchange of oxygen across the sea surface, J. Mar. Res., 7, 347-361, 1948.

Schink, D. R., J. J. Sigalove, R. L. Charnell, and N. L. Guinasso, Jr., Use of $\mathrm{Rn} / \mathrm{Ra}$ ratios to determine air/sea gas exchange and vertical mixing in the ocean, Rep. Paltr 205, p. 43, Teledyne Isotop., Palo Alto, Calif., 19

Schulkin, M., The propagation of soun in imperfect ocean surface ducts, Rep. 1015, p. 128, U.S. Navy Underwater Sound Lab., N.w London, Conn., 1969.

Turner, W. R., Microbubble persistence in fresh water, J. Acoust. Soc. Amer., 33, 1203-1232, 1961.

Wyman, J., P. F. Scholander, G. A. Ecivards, and L. Irving, On the stability of gas bribles in seawater, J. Mar. Res., 11, 47-62, 195 .

(Received August 2, 1972 ; revised October $31,1972$. 